\title{
Towards more sustainable construction-application of superabsorbent polymers in cementitious matrices with reduced carbon footprint
}

\author{
Agnieszka J. Klemm ${ }^{1}$ and Fernando C.R. Almeida ${ }^{1}$ \\ ${ }^{1}$ Glasgow Caledonian University, School of Engineering and Built Environment, Glasgow, United Kingdom
}

\begin{abstract}
Construction industry is constantly searching for sustainable innovations to mitigate negative environmental impacts. Ground granulated blast-furnace slag (GGBS) is a well-known supplementary cementitious material which contributes to reduction of energy and $\mathrm{CO}_{2}$ emissions from cement industry. However, its use in cementitious systems leads to materials with high cracking susceptibility due to their greater autogenous shrinkage triggered by self-desiccation processes. This problem is even more pronounced when concrete is exposed to severe dry-hot weather conditions, such as in North Africa. In order to mitigate this negative effect of cracking, internal curing agents in the form of Superabsorbent polymers (SAP) can be successfully used. This approach leads to more durable cement based materials and in turn more sustainable constructions.
\end{abstract}

\section{Introduction}

Construction industry is constantly searching for sustainable innovations, which aim to reduce environmental impact and propose more durable solutions for buildings. It is widely accepted fact that Supplementary Cementitious Materials (SCM) reduce energy and $\mathrm{CO}_{2}$ emissions from cement production, improve material's performance as well as reduce wastes from other industries [1-3]. Ground granulated blastfurnace slag (GGBS), a by-product of iron industry, is one of the most popular SCMs. Due to its latent hydraulic property, activated by alkalis/lime present in Portland cement (PC), it can effectively replace up to 95\% of cement [4-8].

One of the most common problems in concrete is its premature drying (self-desiccation), which in turn often results in micro-cracking and a subsequent deterioration. This problem is even more relevant to the concrete structures in regions with high temperatures/low humidity such as those in the North Africa [9-11]. Superabsorbent polymers (SAP) may eliminate or substantially reduce this effect by supplying setting and hardening concrete with additional water resources for internal curing [1216]. Although significant efforts have been made during the last couple of decades there is still a lack of consensus on mechanisms ruling SAP actions in cementitious materials [17-19].

This paper therefore aims to present the current state-of-the-art and to provide an overview of SAP as a new admixture, highlighting its effects in GGBS-PC matrices.

\section{Superabsorbent polymers}

Superabsorbent polymers (SAP) are hydrogels formed by macromolecular networks of hydrophilic polymer chains, with the ability to absorb aqueous fluids. SAPs are lightly crosslinked polyelectrolytes, generally based on ionic monomers, such as acrylamide and acrylic acid, which are partially neutralized with hydroxides of alkali metals (usually sodium). This lightly crosslinked three-dimensional structure displays a high capacity to swell by water absorption (Fig. 1); SAPs can absorb as much water as about 10-1000 g/g [12,20].

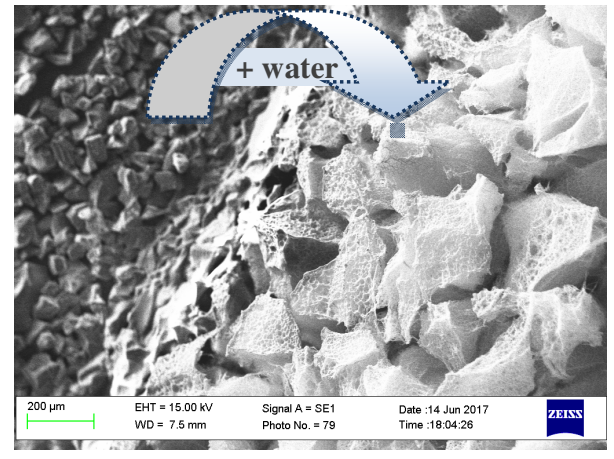

Fig. 1. SAP in contact with water: dry particles (left) and swollen hydrogel (right).

Although SAPs are mainly used in personal disposable hygiene products they also have several other applications, such as in agriculture, pharmaceutics, separation technology, fibers/textiles, water-swelling rubbers, soft actuators/valves, electrical and construction 
[20]. In 2014, 3.12 million tons of SAP was produced worldwide, and its consumption is estimated to be expanded by $20 \%$ by 2018. Six enterprises are responsible for more than $80 \%$ of the global SAP production, concentrated mainly in the USA, Germany, China and Japan [21].

Different SAP applications may lead to different sorption behaviour. The swelling capacity and strength of the polymer network depends not only on the crosslinking density and chemical structure of monomers, but also on the external stimuli surrounding SAP [22]. Highly crosslinked SAPs made of less hydrophilic monomers have lower absorption capacities. On the other hand, polymers with lower anion density may store the absorbed liquid for longer and, eventually, provide very moderate release of solution [20,23].

Such a property is desired especially when SAP is used as internal curing admixture in cement-based materials. SAPs absorb water from fresh mix and release it over time during cement hydration processes, resulting in enhancement of some concrete properties. In this context, both sorption capacity and the kinetics of absorption are highly influenced by $\mathrm{pH}$ and ionic concentration of a pore solution. The complex interaction of di- and trivalent ions (e.g. $\mathrm{Ca}^{2+}$ and $\mathrm{Al}^{3+}$ ) from cement with carboxylate groups results in an additional crosslink and hence reduces SAP absorption capacity [12,23]. Thus, raw materials, in particular type of cement, play an essential role in determining SAP efficiency in concrete and mortars. The use of SCM, in turn, may change the behaviour of absorption and desorption capacity. Fig. 2 illustrates the difference of water absorption capacity over time (up to 24h) in Portland cement (PC) and GGBS filtrates, by means of tea-bag method [23,24]. Although SAP achieved the max absorption capacity in the first minutes for both solutions (around $40 \mathrm{~g} / \mathrm{g}$ ), GGBS systems seems to lead to a faster water release.

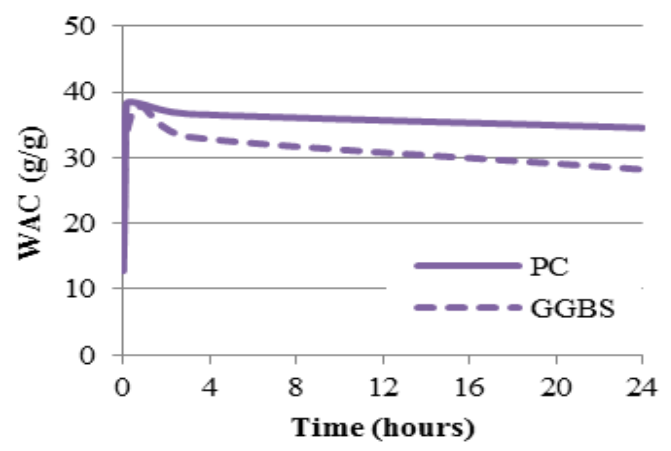

Fig. 2. SAP water absorption capacity in PC and GGBS systems.

In an attempt to show the effect of SAPs on PCGGBS systems, two types of polymers with different water absorption capacities has been considered and presented in this paper. SAP A and SAP B (with water absorption capacities of $10 \mathrm{~g} / \mathrm{g}$ and $25-30 \mathrm{~g} / \mathrm{g}$ in cement paste solution, respectively) have been used in the proportion of $0.25 \%$ of binder mass. Four levels of PC (CEM I 52.5N [8]) replacement by GGBS has been considered: $0 \%, 25 \%, 50 \%$ and $75 \%$. SAP effects on
GGBS-PC matrices were assessed by analysing mortars with binder:sand ratio $1: 2$ and water/binder ratio 0.5 . Samples were named by type of SAP (A, B, Ref - no SAP) and GGBS content $(0,25,50,75)$.

\section{Workability and setting times}

Fresh state properties can be significantly altered by SAP addition, since it absorbs water almost instantly from fresh mix. Thus, sorption characteristics of SAPs are crucial in the determination of early age properties of cementitious matrices. As mentioned previously, many factors can affect SAP absorption capacity and the kinetics of absorption/desorption processes. These include type of polymer (chemical composition and molecular structure), SAP characteristics (shape and size of particles) and type of medium (ions concentration and type of cementitious matrix - e.g. paste, mortar or concrete).

For example, regarding SAP particle sizes, for the same amount of internal curing water, finer particles provide higher values of yield stress and plastic viscosity (drier mixes). This is because of greater total absorption surface of these particles and, consequently, more rapid achievement of equilibrium. On the other hand, larger SAP particles lead to slower water absorption, resulting in less consistent mixes during the first minutes [25].

Moreover, the type of raw materials used in the mix composition can affect rheological properties. The use of finer materials in concrete, such as silica fume, leads to a "competition" between SAP absorption and adsorption of water on finer particles. Thus, it becomes more difficult for SAP to uptake water resulting in reduced workability [25].

Overall, SAP reduces workability of concrete and mortars for the same $w / b$ ratio. This reduction is evidenced by the experimental results of flow table test [26] showed in Fig. 3. Mortars modified by SAPs exhibited lower values than the reference samples (below $140 \mathrm{~mm})$, for all GGBS contents. Also, due to the fineness of GGBS, a slight reduction in flow values was noticed for higher PC replacement levels.

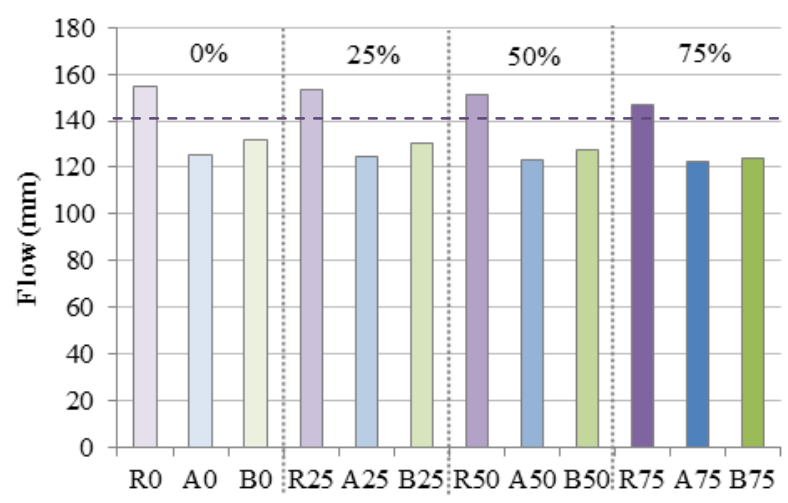

Fig. 3. Flow results of PC-GGBS mortars modified by SAPs.

Nonetheless, this drawback in reduced workability by SAPs can be minimized or even eliminated by using additional water and/or superplasticizer [13,25,27]. 
However, any of these additional efforts, as any other chemical admixture, should be carefully evaluated beforehand. For instance, increasing w/b ratio may improve workability but also result in higher water absorption by SAP, and consequently, in higher relative changes of rheological parameters [25]. Also, the use of superplasticizer can alter ionic concentration of the medium and hence change SAP sorption behaviour.

Regarding setting time, there is still no consensus whether SAPs increase or decrease this property. Significant scatter in experimental results can be due to variations of raw materials, type and particle size of SAPs, accuracy of test methods [28] and to the fact that SAPs can leach out some monomers into the fresh mix $[13,25,29]$. Fig. 4 supports this statement. Cement composition and type of SAP can lead to different values of setting times compared to the reference mortars.

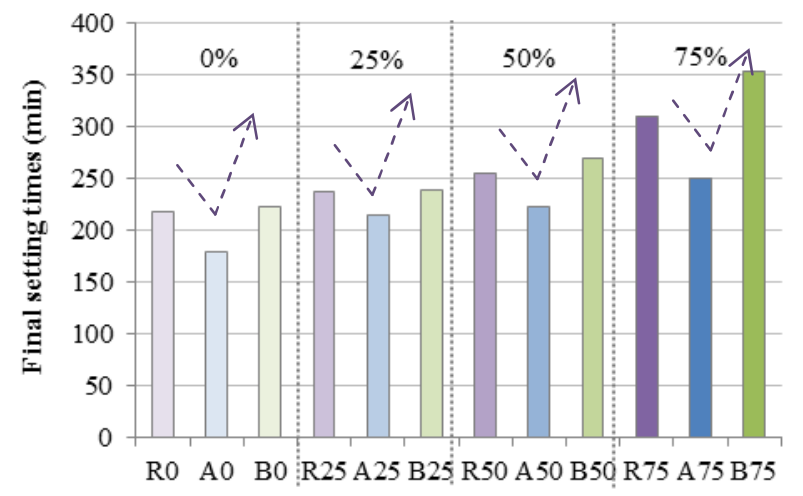

Fig. 4. Setting time results of PC-GGBS mortars modified by SAPs.

While SAP A reduced setting time, SAP B had an opposite effect. This difference is even more considerable for an increased GGBS content in the mix (above 50\%).

\section{Cracking susceptibility}

The main and most well accepted application of SAP in cementitious materials is for the reduction of cracking susceptibility triggered by self-desiccation process. SAP capacity to store and supply water over time can significantly mitigate the effects of volume changes in concrete due to shrinkage, in particular those related to autogenous deformations. Fig. 5 shows that all SAP samples displayed reduced autogenous shrinkage compared to the reference samples. Results cover the period between final setting time and 7 days [30].

Autogenous shrinkage is a result of cement hydration process during hardening of concrete. The use of SAP as an internal curing agent leads to changes in thermodynamics and kinetics of cement reaction due to additional quantity and availability of water. This effect can also contribute to reduction of other types of deformations, such as those provoked by plastic and drying shrinkage [12].
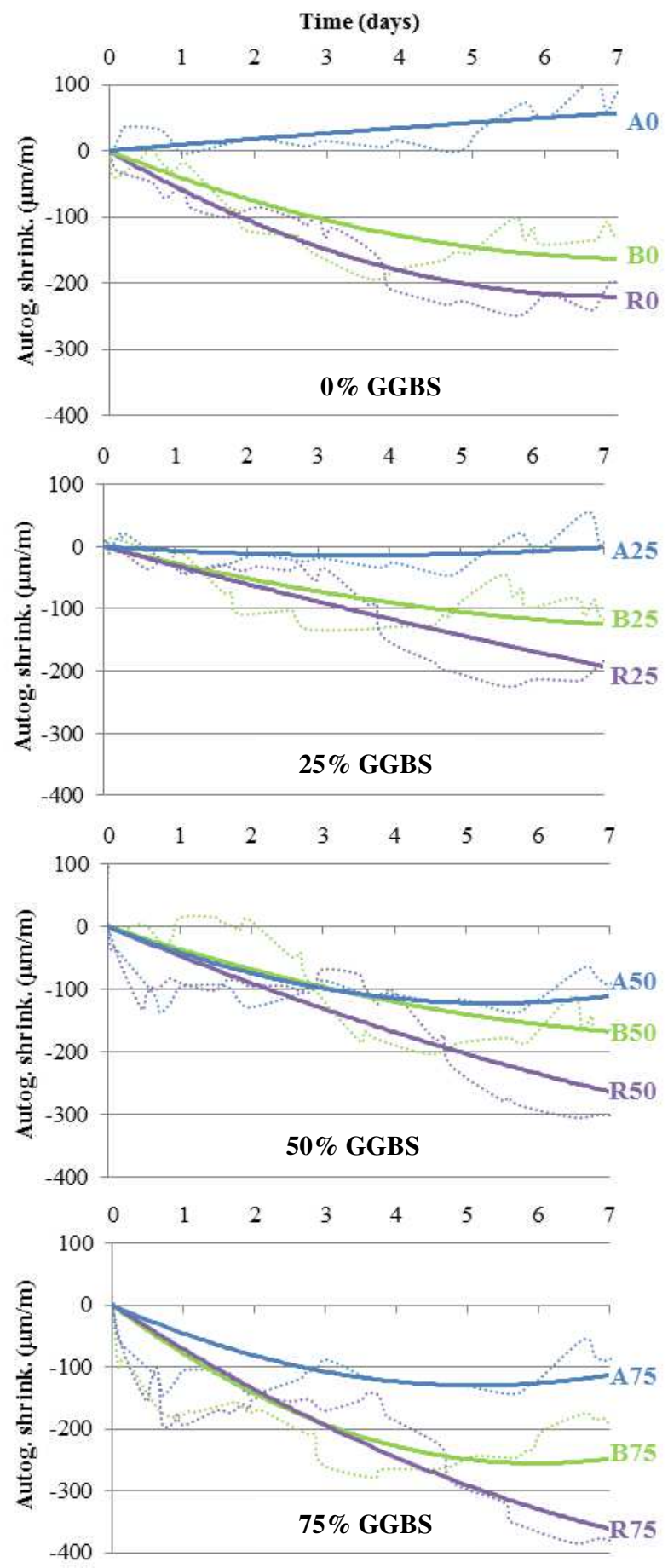

Fig. 5. Autogenous shrinkage results of PC-GGBS mortars modified by SAPs.

Kinetics of absorption and desorption of SAPs plays a major role in mitigation of autogenous shrinkage. The slower water release, the better internal curing. Usually, high anionicity SAPs show an intense release of absorbed pore solution during the first few hours. While it is efficient in reducing autogenous shrinkage at early age, this positive effect disappears when the rest of internal curing water is consumed. Thus, the increase in autogenous shrinkage starts to take place with the same pace as in SAP-free concrete. However, SAPs with low anion concentration, which do not exhibit any, or just a very moderate release of pore solution, can be used to 
reduce autogenous shrinkage for longer periods of time $[13,23]$.

SAPs can also have slower water intake extending even after setting time (from bleeding water). In this case, an expansion can be observed, which counteracts an expected shrinkage in cementitious matrices (e.g. SAP A for low GGBS levels in Fig. 5). This expansion is also a function of the cement chemistry and the admixture dosage; SAP increases the portlandite oversaturation level in solution, which can result in higher crystallization stresses, and hence lead to a material expansion [18,31].

Concrete composition and type of raw materials also contributes to the SAP behaviour in reducing shrinkage. High performance concrete (lower w/b ratio), for example, is very prone to early age cracking induced by self-desiccation and autogenous deformation [13,15]. High content of GGBS also leads to increased chemical shrinkage due to its filler effect and greater hydration degree $[1,4,5]$. Thus, SAPs showed themselves as a great shrinkage reducer in GGBS-PC matrices (Fig. 5).

Thus, cracking susceptibility by shrinkage deformation is very dependent to the amount of water available for hydration and curing of GGBS cementitious systems. In this context, creating mechanisms that contribute to controlling of water supply is essential for the material durability, especially in hot and dry climates due to high surface evaporation rate. For example in regions such as in North Africa, day temperature may reach $43^{\circ} \mathrm{C}$ in summer with amplitude between day and night often reaching about $18^{\circ} \mathrm{C}$. The relative humidity (RH) level of air can reach $24 \%$ (Table 1) [9].

Table 1. The monthly mean climatic data in North Africa (Ouargla Algeria region) [9].

\begin{tabular}{|c|c|c|c|c|c|c|}
\hline & Jun & Jul & Aug & Sep & Oct & Nov \\
\hline $\mathrm{T}_{\max }\left({ }^{\circ} \mathrm{C}\right)$ & 39.8 & 43.2 & 42.2 & 37.6 & 30.7 & 23.6 \\
\hline $\mathrm{T}\left({ }^{\circ} \mathrm{C}\right)$ & 31.5 & 34.3 & 33.6 & 29.8 & 23.4 & 16.6 \\
\hline $\mathrm{T}_{\min }\left({ }^{\circ} \mathrm{C}\right)$ & 23.2 & 25.3 & 25.0 & 22.0 & 16.0 & 9.6 \\
\hline $\mathrm{RH}(\%)$ & 28.5 & 24.4 & 26.4 & 34.4 & 47.6 & 56.5 \\
\hline
\end{tabular}

It has been well documented that in this type of environment, conventional concrete and mortars exhibit high level of shrinkage and cracking [9-11].

Therefore, the higher shrinkage triggered by GGBS, especially in critical wheatear conditions, the greater the need for SAPs. It helps to keep durability and sustainability in acceptable levels for cementitious matrices, particularly in avoiding crack formation.

\section{Mechanical properties}

The use of SAP with additional water generally can lead to losses in strength. However, it can be partly recovered with time due to ongoing hydration facilitated by the internal curing mechanisms [17,23]. SAP promotes creation of a dense network of $\mathrm{CSH}$ in a collapsed state, and hence leading to pore closures and increased compressive strength [16,19,32].

This recovery depends on SAP efficiency in water supply during cement hydration. Premature release of water (before setting) leads to a decrease in compressive strength. This is attributed to some increase in effective $\mathrm{w} / \mathrm{b}$ (due to additional water for internal curing) and subsequently higher porosity of concrete. In contrast, for mixes with SAP that do not exhibit an early water release, no significant decrease in strength is observed due to its capacity to release water in later stages [13,23].

However, other factors can contribute to strength level, such as, shape and size of SAP particles. Spherical SAPs and smaller particles lead to higher compressive strengths in comparison to mixes with irregular and larger particles. This is because higher stress concentration in combination with larger voids left by collapsed SAP has a strong impact on mechanical properties in the hardened state [13].

In case of GGBS-PC matrices, it is expected that the hydration processes last longer due to slower reaction of slag compared to Portland cement. This delay in GGBS hydration is related to its chemical composition, fineness, glass content, temperature, and to the fact that GGBS has to be activated by alkalis/lime to start to form $\mathrm{CSH}[2,6]$. In this case, the presence of SAP plays an important role in providing water for longer period.

However, the type of cement can also have an effect on the SAP performance (see Fig. 2). This effect on compressive strength can be observed in Fig. 6 [33].

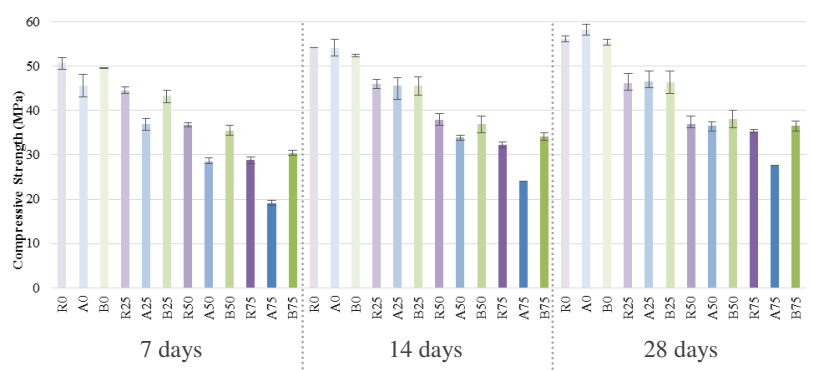

Fig. 6. Compressive strength results of PC-GGBS mortars modified by SAPs.

For low GGBS contents, the effect of SAP on compressive strength is very limited. However, for higher GGBS contents, the effect of SAP type is more pronounced. SAP B, with higher absorption capacity, is able to store and provide more water for hydration for any PC-GGBS system. Thus, it can lead to higher densification of cementitious matrix resulting in a slight increment in compressive strength up to 28 days. On the other hand, SAP A, with lower WAC, has significantly decreased compressive strength for high GGBS contents. This can be related to the instability of the polymer that is not able to retain water for longer (after one week), leaving behind pores that negatively affect compressive strength. This effect on pore formation is discussed in the following paragraph. 


\section{Microstructure alterations}

When SAP absorbs water from fresh mix, it turns to a gel and swells in the mixture. This gel is therefore responsible for storage and release of water for internal curing in cementitious matrix. In other words, this water desorption happens (or should happen) simultaneously with the hardening process leading to a substantial modification of the skeleton formed by hydrated products. Such alterations can be related to the voids created by collapsed SAPs, when gel polymer releases absorbed water and, in consequence, leave behind pores in the hardened microstructure. Although these pores can be filled with later hydration products (especially for GGBS-PC), microstructure alterations are directly dependent on SAP absorption, storage capacity and desorption rate in each cementitious reacting system. Fig. 7 schematically represents the modification of cementitious systems by SAP.

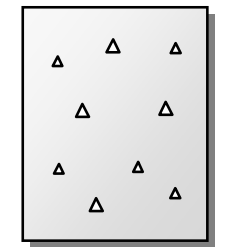

(a)

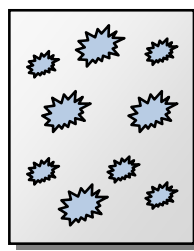

(b)

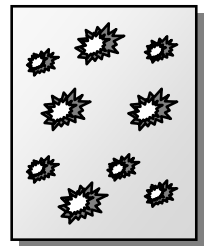

(c)
Fig. 7. SAP modifications in cementitious systems. (a) dry mix with dry SAP particles; (b) fresh matrix with swollen SAP particles filled with water (gel); (c) hardened matrix with collapsed SAPs and voids partially filled with cement hydration products.

When capillary pores $(10 \mathrm{~nm}-10 \mu \mathrm{m})$ are analysed, it is expected that SAPs increase total porosity due to macro-pore formation, especially when additional water is considered [34]. In the case of smaller pores, additional amounts of water do not significantly affect micropore range $(<2 \mathrm{~nm})$ and slightly increase mesopore range (2$50 \mathrm{~nm})$ [35].

Reduction of smaller capillaries is observed in matrices modified by SAPs without extra water. This is due to the filling of existing pores with hydration products and the reduction of initial micro cracks caused by now mitigated autogenous shrinkage. Thus, the microstructure around SAPs is denser due to internal curing and unconnected macropores [32,35,36].

GGBS can also have an impact on the microstructure of cement based matrices. Its ability to slow down cementitious reactions and induce a filler effect leads to a denser $\mathrm{CH}$-laden interfacial zone and formation of finer capillaries, in particular, those in the mesopore range $[1,2,6,36]$.

Fig. 8 shows an example of how different types of polymers can influence porosity of GGBS-PC matrices. SAP A is able to create more pores, since it was not completely filled with hydrated products in the collapsed state. This polymer has presented the highest peaks for all samples.
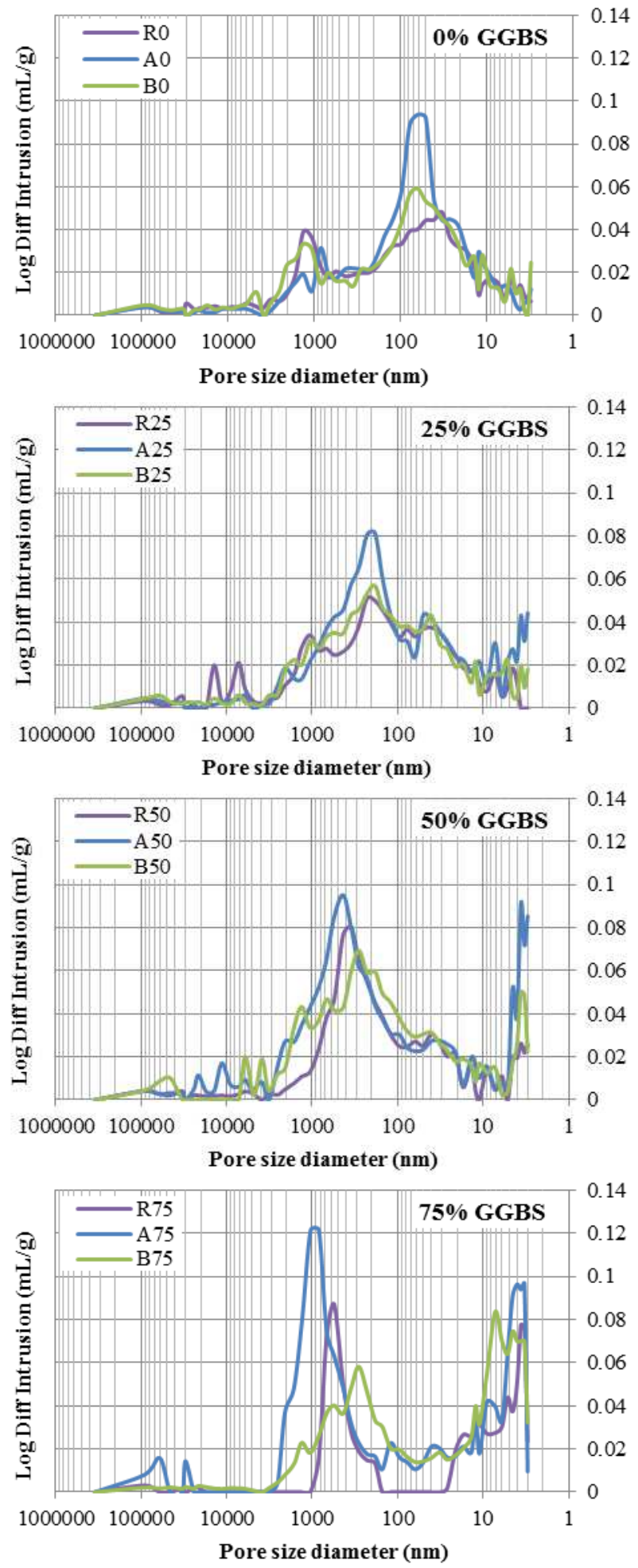

Fig. 8. Pore size distribution of PC-GGBS mortars modified by SAPs at 28 days.

However, for higher GGBS contents (from 50\% onwards), both SAPs have created larger capillary pores (above $1 \mu \mathrm{m}$ ) when compared to the reference sample; SAP A formed the largest pore sizes (curves shifted to the left) indicating the weakness of this polymer in sustaining slower and later GGBS hydration. In turn, SAP B (with higher water absorption capacity) showed more efficiency in decreasing the amount of larger pores for higher GGBS contents. 


\section{Final remarks}

Superabsorbent polymer (SAP) is a promising new admixture particularly in cementitious materials with reduced carbon footprint (GGBS-PC). Its efficiency in providing water for internal curing results in reduced autogenous shrinkage and, consequently, lower susceptibility for cracking. However, its application in GGBS-PC matrices has to be carefully evaluated, since the effects of different types of SAPs depend on different GGBS concentrations. Overall, SAPs reduce workability and may increase total porosity of concrete in hardened state. Its ability in re-filling the pores (left by collapsed SAPs) and maintaining similar mechanical properties depends on its capacity to store and release water for longer, especially when GGBS is considered (slower reaction rate). SAPs can reduce smaller capillaries with further hydration products, creating a denser and poorly interconnected microstructure. This, in turn, may lead to more durable cement based materials and more sustainable constructions.

\section{Acknowledgments}

The authors acknowledge CNPq (National Council for Scientific and Technological Development - Brazil) for the financial support, Hanson Cements for CEM I and GGBS supply, and BASF for SAPs supply.

\section{References}

[1] K.L. Scrivener, B. Lothenbach, N. De Belie, E. Gruyaert, J. Skibsted, R. Snellings, A. Vollpracht, Mater. Struct. 48 (2015) 835-862.

[2] M. Thomas, Cem. Concr. Res. 41 (2011) 12241231.

[3] R. Siddique, M.I. Khan, Supplementary Cementing Materials, Springer, Berlin, 2011.

[4] K.L. Scrivener, P. Juilland, P.J.M. Monteiro, Cem. Concr. Res. 78 (2015) 38-56.

[5] K.M. Lee, H.K. Lee, S.H. Lee, G.Y. Kim, Cem. Concr. Res. 36 (2006) 1279-1285.

[6] R. Siddique, R. Bennacer, Resour. Conserv. Recycl. 69 (2012) 29-34.

[7] M. Ben Haha, B. Lothenbach, G. Le Saout, F. Winnefeld, Cem. Concr. Res. 42 (2012) 74-83.

[8] BS EN 197-1 (2000).

[9] A. Kriker, G. Debicki, A. Bali, M.M. Khenfer, M. Chabannet, Cem. Concr. Compos. 27 (2005)

[10] K.. Hassan, P.. Robery, L. Al-Alawi, Cem. Concr. Compos. 22 (2000) 453-458.

[11] A.A. Alekrish, S.H. Alsayed, , Cem. Concr. Compos. 16 (1994) 299-307.

[12] V. Mechtcherine, H.-W. Reinhardt, eds., Springer, RILEM, 2012.

[13] V. Mechtcherine, M. Gorges, C. Schroefl, A. Assmann, W. Brameshuber, A.B. Ribeiro, D. Cusson, J. Custódio, E.F. Silva, K. Ichimiya, S. Igarashi, A. Klemm, K. Kovler, A.N. Mendonça Lopes, P. Lura, V.T. Nguyen, H.-W. Reinhardt, R.D.T. Filho, J. Weiss, M.
Wyrzykowski, G. Ye, S. Zhutovsky, Mater. Struct. 47 (2013) 541-562.

[14] A.J. Klemm, F.C.R. Almeida, Concr. Plant Int. J. (2016) 38-46.

[15] S. Zhutovsky, K. Kovler, A. Bentur, Cem. Concr. Res. 41 (2011) 981-986.

[16] A.J. Klemm, K.S. Sikora, Constr. Build. Mater. 49 (2013) 134-143.

[17] H. Beushausen, M. Gillmer, M. Alexander, Cem. Concr. Compos. 52 (2014) 73-80.

[18] D. Snoeck, O.M. Jensen, N. De Belie, Cem. Concr. Res. 74 (2015) 59-67.

[19] A.J. Klemm, F.C.R. Almeida, K.S. Sikora, Concr. Plant Int. J. (2016) 50-58.

[20] M.J. Zohuriaan-Mehr, H. Omidian, S. Doroudiani, K. Kabiri, J. Mater. Sci. 45 (2010).

[21] Market Research Reports, (2015). http://www.rnrmarketresearch.com/global-and-chinasuperabsorbent-polymers-sap-industry-report-2014-2018market-report.html.

[22] W. Siriwatwechakul, J. Siramanont, W. VichitVadakan, Int. RILEM Conf. Use Superabsorbent Polym. Other New Addit. Concr., RILEM, Lyngby, 2010: pp. 253-263.

[23] C. Schröfl, V. Mechtcherine, M. Gorges, Cem. Concr. Res. 42 (2012) 865-873.

[24] C. Schroefl, V. Mechtcherine, P. Vontobel, J. Hovind, E. Lehmann, Cem. Concr. Res. 75 (2015) 1-13.

[25] V. Mechtcherine, E. Secrieru, C. Schröfl, Cem. Concr. Res. 67 (2015) 52-65.

[26] BS EN 1015-3 (2006).

[27] L. Senff, R.C.E. Modolo, G. Ascensão, D. Hotza, V.M. Ferreira, J.A. Labrincha, Constr. Build. Mater. 95 (2015) 575-584.

[28] BS EN 196-3 (2005)

[29] D. Snoeck, D. Schaubroeck, P. Dubruel, N. De Belie, Constr. Build. Mater. 72 (2014) 148-157.

[30] ASTM-C1698-09 (2009).

[31] G. Sant, B. Lothenbach, P. Juilland, G. Le Saout, J. Weiss, K. Scrivener, Cem. Concr. Res. 41 (2011) 218229.

[32] F. Wang, J. Yang, S. Hu, X. Li, H. Cheng, Cem. Concr. Res. 81 (2016) 112-121.

[33] BS EN 1015-11 (2006).

[34] V. Mechtcherine, C. Schroefl, M. Wyrzykowski, M. Gorges, P. Lura, D. Cusson, J. Margeson, N. De Belie, D. Snoeck, K. Ichimiya, V. Falikman, S. Friedrich, Mater. Struct. 50 (2017).

[35] D. Snoeck, L.F. Velasco, A. Mignon, S. Van Vlierberghe, P. Dubruel, P. Lodewyckx, N. De Belie, Cem. Concr. Res. 77 (2015) 26-35.

[36] F.C.R. Almeida, A.J. Klemm, in: 14th Int. Conf. Durab. Build. Mater. Components, PRO 113, Ghent, 2017: pp. 205-216. 